\title{
Assessment of Factors Influencing Youth Involvement in Horticulture Agribusiness in Tanzania: A Case Study of Njombe Region
}

\author{
Adella Albert Ng'atigwa $^{1, *(\mathbb{D}}$, Aloyce Hepelwa ${ }^{1}$, Mastewal Yami ${ }^{2}$ and Victor Manyong ${ }^{3}$ \\ 1 Department of Agricultural Economics and Business, University of Dar es Salaam, P.O. Box 35134, \\ 0701122 Dar es Salaam, Tanzania; ahepelwa@yahoo.com \\ 2 International Institute of Tropical Agriculture (IITA), P.O. Box 5689, 1000 Addis Ababa, Ethiopia; \\ myami29@gmail.com \\ 3 International Institute of Tropical Agriculture (IITA), P.O. Box 34441, 0701252 Dar es Salaam, Tanzania; \\ v.manyong@cgiar.org \\ * Correspondence: adellahn@gmail.com; Tel.: +255-754-739996
}

Received: 17 May 2020; Accepted: 6 July 2020; Published: 10 July 2020

\begin{abstract}
Involvement of youth in horticulture agribusiness has become a vital approach to create employment opportunities among the youth in Tanzania. This study aimed at examining the extent of youth participation and factors influencing youth involvement in horticulture agribusiness with a focus on innovations in post-harvest management (PHM). Data were collected from a sample of 576 male and female youth in Njombe region using a multi-stage random sampling technique. Data were analyzed using an ordered logit model and descriptive statistics. Results of the ordered logit analysis showed that primary school education, Form IV and above, management innovation, access to credit, good perception of horticulture for agribusiness and improved packaging materials positively and significantly influence youth involvement in horticulture agribusiness. Gender and land size had a negative and significant influence on youth involvement in horticulture agribusiness, as indicated by higher percentages of male youth (59\%) participation in the horticulture agribusiness. Therefore, this study suggests increased investment in capacity development of the youth on PHM innovations and the development of rural infrastructure such as agro-processing and storage facilities by the government and private sector. Increasing the availability of improved packaging materials and provision of youth-friendly credit schemes could encourage youth in horticulture agribusiness.
\end{abstract}

Keywords: youth; agribusiness; gender equity; horticulture; postharvest losses; Tanzania; youth unemployment

\section{Introduction}

Over one million youth within the age range of 15 to 24 years were unemployed in Tanzania [1]. About $67 \%$ of the labor force in Tanzania is comprised of young people within the age range of 15 and 35 years. However, this labor force has little or no access to employment opportunities [2]. The situation is unfortunate in that the youth could provide an opportunity for economic development through their involvement in agribusiness and other rural agricultural activities [3].

There is a significant relationship among economic development, employment, investment growth rates, and poverty reduction [3]. Youth could make important contributions to agricultural development if empowered with proper facilities such as access to land, education, market, storage facilities, and financial support. The agriculture sector is the key economic activity in rural areas in Tanzania. For instance, agriculture accounts for about $65.5 \%$ of employment, about $29 \%$ of Gross Domestic Product, $30 \%$ of export earnings, and $65 \%$ of industrial raw materials [4]. Therefore, the agriculture 
sector has the potential of providing solutions to the challenges of youth unemployment in Tanzania. However, some challenges make the sector less attractive to youth. These challenges include economic factors such as limited access to land, low access to credit facilities, low profit margins, and limited accessibility of the market. Social factors include low level of education, less contact with extension officers, negative attitude towards agriculture, and parental influence. Environmental factors include unfavorable weather condition, pests, and diseases which attack horticulture crops [5].

In fact, youth involvement in agriculture is a recent phenomenon as governments in Africa, including Tanzania, have made commitments to engage youth in agribusiness as a strategy to address youth unemployment. Moreover, the youth's tendency to be energetic, innovative, and risk takers could provide an opportunity to transform the agricultural sector in Africa which has been dominated by older people with an average age of 60 to 70 years old [6]. On this basis, African leaders' commitments are reflected in several initiatives such as the adoption of the African Youth Charter (AYC) by the African Union in 2006, the declaration of the African Youth Decade (2009 to 2018), and the establishment of the Youth Desk in the New Partnership for Africa's Development (NEPAD) [6].

At the country level, the Tanzanian Government has developed various development programs to promote youth involvement in the agriculture sector. Currently, the Government of Tanzania through the Ministry of Agriculture has developed the National Strategy for Youth Involvement in Agriculture (NSYIA) for 2016-2021 with a vision of empowering youth to participate fully in agricultural development and contributing to national economic growth [3]. Additionally, the government has developed many programs and strategies such as the Agricultural Sector Development Programme which encourages the inclusion of youth in all agricultural programmes, and the Tanzania Agriculture and Food Security Investment Plan which promotes youth employment in agriculture for increased agricultural productivity, food and nutrition security, and income [7,8]. Moreover, the National Agricultural Policy seeks to involve youth in agriculture by providing an opportunity for increased economic development particularly in agriculture [9].

In Tanzania, horticulture is the fastest growing agricultural sub-sector with an annual average growth rate of $11 \%$ [10]. This growth rate is higher than the overall growth rate of the agriculture sector [11]. Currently, horticulture generates about USD 600 million, equivalent to TZS 1.38 trillion per annum [12]. The sub-sector also provides formal and informal employment opportunities for about 4.4 million people [10]. The horticulture sub-sector could attract youth due to its potential for quick economic returns and its less demand for land compared to staple crops [10]. The labor-intensive nature of the horticulture agribusiness could also mean that the youth cold engage in different production stages such as planting, weeding, and harvesting [12]. However, the employment of youth in the horticulture agribusiness is minimal compared to the huge potential of the sub-sector. The problem could emanate from the perishable nature of the produce which results in a high level of post-harvest losses (PHLs) estimated at 30 to 70\% [13-16]. Postharvest losses (PHLs) refer to the measurable loss of food (i.e., quality and/or quantity) along the supply chain from the time of harvest to consumption or other end users [17].

This study examines the factors influencing youth involvement in horticulture agribusiness with a focus on innovations in post-harvest management (PHM). First, the study determines the extent of involvement of male and female youth in the horticulture agribusiness. Second, the study identifies factors influencing the involvement of male and female youth in the horticulture agribusiness with a focus on PHM innovations. Third, the study quantifies PHLs encountered by male and female youth involved in the horticulture agribusiness. The study findings are expected to contribute significantly towards the global and national efforts of increasing food and nutrition security, employment opportunities, and poverty reduction through promoting youth participation in agriculture. Therefore, the findings are expected to meet the National Strategy for Growth and reduction of poverty and Millennium Development goals.

The rest of the paper is organized as follows. The Sections 1.1 and 1.2 present the conceptual framework and discusses the reviewed literature. Section 2 presents the methods. Section 3 presents 
results and discussions. Then, Section 4 highlights the conclusions and policy implications of the findings.

\subsection{Conceptual Framework}

The framework guiding this study includes factors influencing youth involvement in horticulture agribusiness with a focus on innovations in PHM (Figure 1). The factors are categorized into three groups. The independent variables include economic factors, social factors, and envirnmental factors. The moderating variables are represented by government policies and regulations. Policy measures can influence the above factors to produce positive results. The youth involvement in horticulture agribusiness is the dependent variable. The conceptual framework was used to guide data generation and analysis.

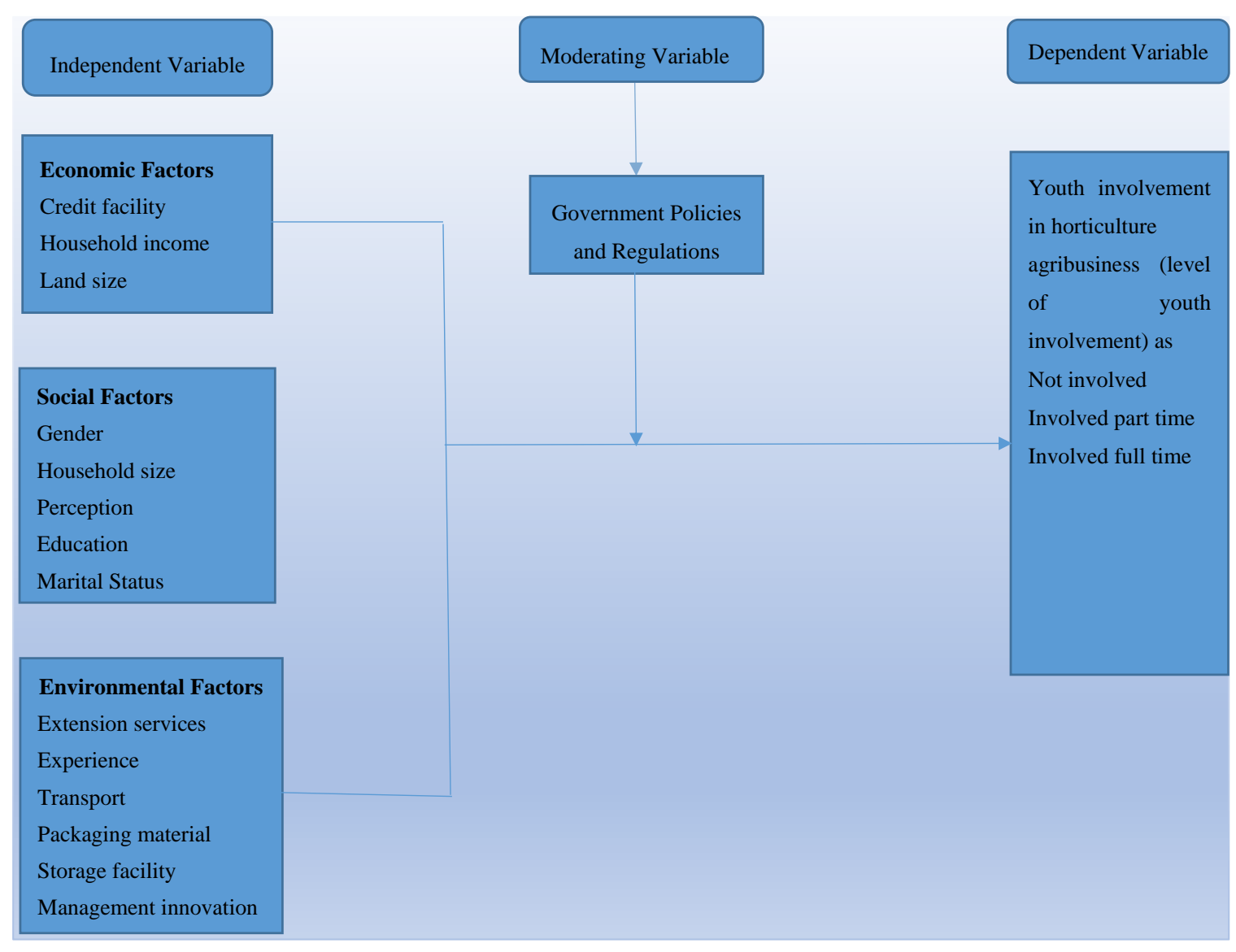

Figure 1. Conceptual Framework. Source: Modified from [18].

\subsection{Literature Review}

Several studies focusing on youth involvement in agribusiness as a strategy towards youth employment opportunities in developing countries. For example, Ref. [6] used the deductive coding approach and their results found that interventions that integrate capacity development, financial support for startups, and continuous mentorship on the technical and financial aspects proved successful in enhancing youth engagement in agribusiness. Additionally, Ref. [19] used a logistic regression model to analyze "Determinants of youth" participation in rural agriculture in Imo State, Nigeria. Their empirical results revealed that age, marital status, education, household size, parents' occupation, parents' farm income, and dependence status were significant factors influencing youth participation in agricultural activities. Similarly, Ref. [5] on determinants of decision and participation of rural youth in agricultural production in Nigeria used the logistic model. The empirical 
results revealed that years of youth in social organizations, access to Information and Communications Technology (ICT), nature of land ownership, and access to state-owned agricultural programs positively determined the decision of youth to engage in agricultural activities in the study area [20] examined the constraints to rural youth involvement in agricultural production in Kwara State, Nigeria. Their results found that lack of agricultural insurance, poor returns to agricultural investments, lack of basic farming knowledge, and lack of access to farm inputs were the major constrains limiting youth involvement in agricultural production. A study carried out by [21] assessed and quantified losses along the tomato postharvest value chain in three agroecological zones of Ghana. Results found that losses during harvest across regions ranged between 4.6 and $10.85 \%$ with the highest in Upper Eastern region of Ghana. During grading and packing between 3.6 and $13.75 \%$ of fruit was lost, 2.3 to $7.4 \%$ during transportation, and 2.6 to $3.3 \%$ during marketing, Ref. [15] found that a huge loss of oranges (about $56 \%$ ) occurred at farm level due to poor practices of farmers and harvesters and inadequate facilities during harvesting, handling, and storage in the Coast Region of Tanzania [22] on their assessment of postharvest loss and quality deterioration of horticultural crops in Dire Dawa Region, Ethiopia used descriptive statistics to estimate postharvest losses. Results revealed that climate and weather conditions, harvesting and handling techniques, and disease and pests were recorded as major causes for postharvest losses. The study further found that severe postharvest loss and quality deterioration of horticultural crops mainly occurred during harvesting followed by marketing, transporting, and storage. From the reviewed literature, there is little information on factors influencing youth involvement in horticulture agribusiness with regard to innovations in PHM.

For instance, Ref. $[5,6,19]$ showed how various factors influence youth participation in agribusiness but they did not show how innovations in PHM could influence youth involvement in horticulture agribusiness. Thus, this study was designed to contribute to the literature by closing this identified gap. Findings of this study could assist the government to better understand factors influencing youth participation in horticulture agribusiness and to design proper policies.

\section{Materials and Methods}

\subsection{Study Area}

The study was conducted in the Njombe Region (Njombe Town Council, Njombe District Council, and Makambako Town Council), which is located in the Southern Highlands of Tanzania from November to December 2018. The region covers an area of $21,347 \mathrm{~km}^{2}$ and lies between Longitude $35^{\circ} 00^{\prime} 0.00^{\prime \prime} \mathrm{E}$ and Latitude $9^{\circ} 15^{\prime} 0.00^{\prime \prime} \mathrm{S}$ (Figure 2). According to the 2012 National Census, the total population of Njombe Region was 702,097, while Njombe Town Council had a total population of 130,223, Njombe District Council 85,747, and Makambako Town Council 93,827 people [2]. These districts were selected because of their high potential for horticultural farming. Among the horticultural crops selected were tomato (Solanum lycopersicum), carrot (Daucus carota), cabbage (Brassica oleracea), amaranthus (Amaranthus cruentus), avocado (Persea americana), Brassica (Brassica carinata), and Chinese mallow (Malva verticillata). This is due to their economic importance in the study area. The region is bordered by the Mbeya, Iringa, Morogoro, and Ruvuma regions. Most of the population was engaged in agricultural activities with farming as their major occupation. 


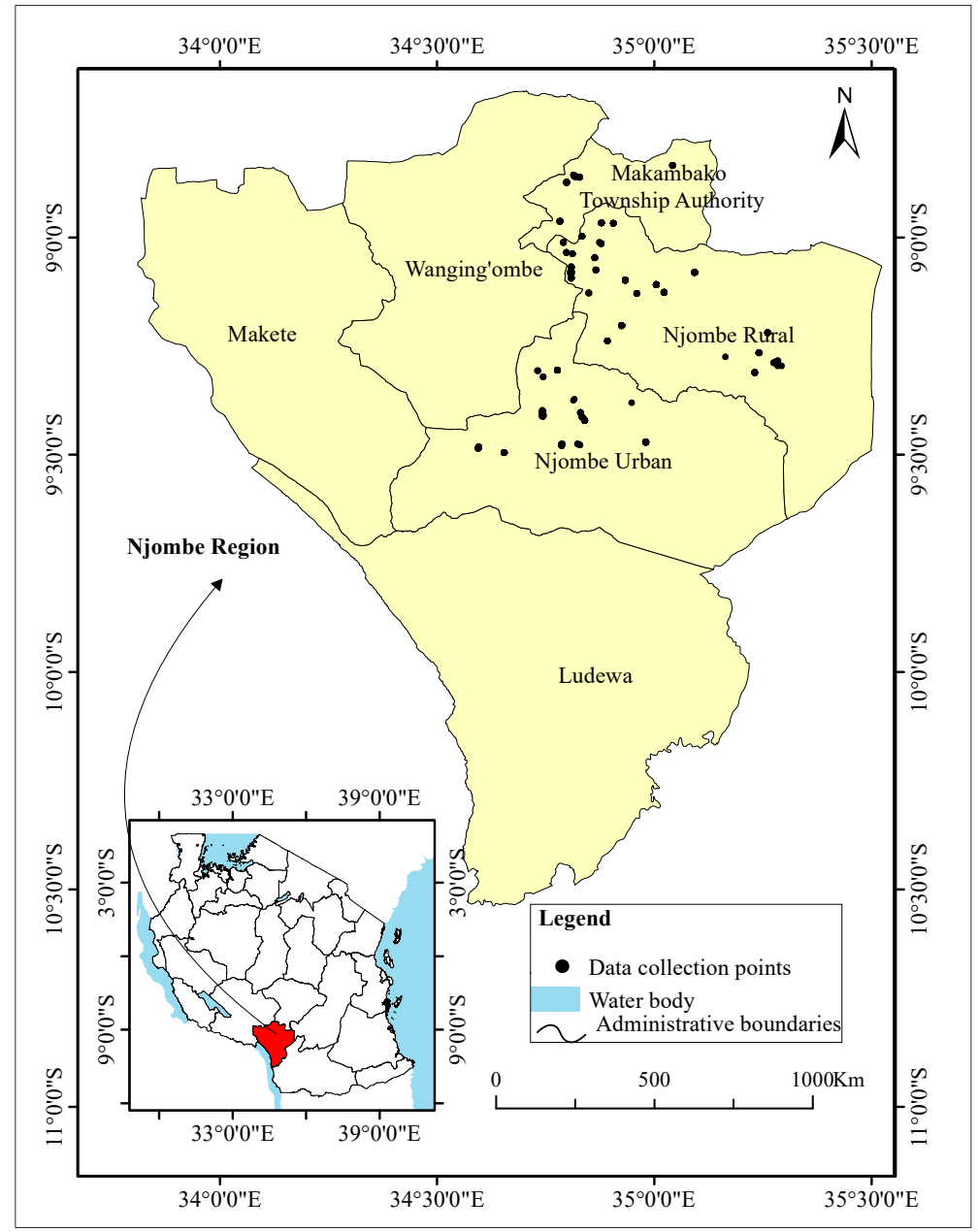

Figure 2. Map of Tanzania showing the study location.

\subsection{Data Generation}

The data for this study were obtained from both primary and secondary sources. Secondary data were obtained from published literature, the Internet, and the Ministry of Agriculture, Tanzania For primary data, the multistage sampling technique was employed to select respondents. At the first stage, Njombe Town Council, Njombe District Council, and Makambako Town Council were purposively selected among the districts in Njombe Region because of their known high production of horticultural crops. At the second stage, the population was set into strata of zones by types of crops cultivated; from these, 16 out of 97 villages of the study districts were purposively selected for the study. Lastly, male and female youth were randomly selected for interview from the list of youth in each village that was developed with the aid of village executive officers. The villages, which were purposefully selected for study according to the potential of horticultural production were Ninga, Nundu, Uwemba, Utengule, Tagamenda, Rwangu, Nyombo, Mfereke, Matiganjola, Igombola, Ihang'ana, Mashujaa, Isitu, Itunduma, Kisilo, and Kitandililo. The study employed a cross-sectional research design whereby both qualitative and quantitative data were collected. A semi-structured questionnaire using electronic surveys on android tablets was administered to respondents. Focus Group Discussions (FGDs) on horticulture production were also conducted with 16 groups. The sample size was determined by using the Cochran formula [23]

$$
\mathrm{n}=\frac{\mathrm{Z}^{2} \mathrm{P}(1-\mathrm{P})}{\mathrm{e}^{2}}
$$


where $\mathrm{n}$ is the sample size, $\mathrm{Z}$ is the statistic for a level of confidence of $95 \%$, which is (1.96), e is the sampling error (level of precision), which was $5 \%$, and $\mathrm{P}$ is the proportion (prevalence), which is $67 \%$ for this study. By using the formula in Equation (1), 576 rural youth were sampled in the study districts.

\subsection{Data Analysis}

\subsubsection{Descriptive Statistics}

Descriptive statistics were used to provide insights into the extent of male and female youth involvement in horticulture agribusiness with a focus on innovations in PHM that there is no difference in percentage between male and female youth involvement in horticulture agribusiness.

\subsubsection{Econometric Analysis}

Ordered logit model (OLM) was used to identify factors contributing to male and female youth involvement in horticulture agribusiness, particularly in PHM innovations. OLM was performed to test the hypotheses that socio-economic factors and environmental factors do not influence the decision of male and female youth to engage in horticulture agribusiness. OLM is a regression model for an ordinal response variable, which is based on the cumulative probabilities of the response variable. The logit of each cumulative probability is assumed to be a linear function of the covariates, with regression coefficients constant across response categories [24]. The ordered logit model is appropriate for ordered, categorical variables such as no involvement, part-time involvement, and full-time involvement. One interpretation of the ordinal model is that the probability of selecting a particular number of practices is a function of an underlying latent variable that measures a youth's utility for being involved in horticulture agribusiness. OLM is good for quantifying the effects of the contributing factors on ordinal response variables while avoiding losing valuable information about the ordering. This is because despite being ordered, the scores are not continuous outcomes or normally distributed [25]. The ordered logit model is given by Equation (2);

$$
\mathrm{Y}^{*}=\mathrm{X}^{\mathrm{T}} \beta_{\mathrm{i}}+\varepsilon
$$

where $Y^{*}=$ unobserved dependent variable, $X^{\mathrm{T}}$ is the vector of independent variables, $\beta_{\mathrm{i}}$ is the vector of regression coefficients and $\varepsilon$ is the error term

The latent variable (level of involvement) in this study exhibits itself in ordinal categories, which was coded as $0,1,2 \ldots j$. The response category $\mathrm{j}$ is thus observed when the underlying continuous response falls in the $j$-th interval as:

$$
Y^{*}=\left\{\begin{array}{l}
0, \text { if } Y^{*} \leq \delta \\
1, \text { if } \delta_{0} \leq Y^{*} \leq \delta_{1} \\
2, \text { if } \delta_{1} \leq Y^{*} \leq \delta_{2} \\
N, \text { if } \delta_{N} \leq Y^{*}
\end{array}\right.
$$

where $Y^{*}(i=0,1,2 j)$ is the unobservable threshold parameters that were estimated with the other parameters in the model, $\delta$ is the standard deviation and $\mathrm{N}$ is the number of categories of the ordered response variables. Refs. [26,27] noted that when an intercept coefficient is included in the model, $\mathrm{Y}_{0}{ }^{*}$ is normalized to zero value, and hence only $\mathrm{N}-1$ additional parameters are estimated with $\mathrm{X}^{\prime} \mathrm{s}$.

An ordered logit model can be written in terms of probability of youth involvement in horticulture agribusiness with a focus on PHM. In this study, the level of youth involvement in horticulture agribusiness is specified in Equation (3);

$$
P\left(y_{i}>j\right)=\frac{\exp \left(X_{i} \beta-\varnothing_{j}\right)}{1+\exp \left(X_{i} \beta-\varnothing_{j}\right)} \quad j=0,1 \ldots M-1
$$


where $j$ is ordered response category, $X_{i}$ is a vector of observed explanatory variables, $\beta$ is a vector of parameters to be estimated, $\varnothing_{j}$ are cut points for the thresholds of the ordered model, $P$ is the probability of youth involvement in horticulture agribusiness, $y_{i}$ is the dependent variable and $M$ is the number of categories of the ordered response variables.

The conceptual framework as depicted in Figure 1 guided the econometric analysis.

\subsubsection{Dependent Variable}

The dependent variable (i.e., level of involvement) was selected based on the huge potential of the horticulture sub-sector to absorb a large proportion of unemployed youth in Tanzania. Factors including quick economic returns, limited land requirement, and the high demand for labor to undertake activities such as harvesting, grading, packaging, storage, transportation, and marketing contribute to the increased potential of youth employment in horticulture agribusiness. The OLM was specified for the study as follows:

Let $Y_{i}$ denote the level of involvement: Not involved $\left(Y_{0}=0\right)$, Part-time $\left(Y_{1}=1\right)$, Full-time $\left(Y_{2}=2\right)$ in horticulture agribusiness regarding innovations in PHM.

\subsubsection{Independent Variables}

In this study, the independent variables were socio-economic characteristics such gender, marital status, education, household size, access to extension services, access to credit, experience in farming, land size, and household income from horticulture, and environmental factors such as the good perception of horticulture agribusiness, improved packaging, improved storage facilities, and improved transport facilities (Table 1).

Table 1. Independent variables and descriptive statistics.

\begin{tabular}{|c|c|c|c|c|}
\hline Variable & $\mathbf{N}$ & Expected Sign & Mean & SD \\
\hline Gender $($ male $=0$, female $=1)$ & 576 & - & 0.405 & 0.491 \\
\hline Marital status (married $=1$, unmarried $=0$ ) & 576 & + & 0.746 & 0.435 \\
\hline Education: Primary education $($ yes $=1$, no $=0$ ) & 576 & - & 0.635 & 0.482 \\
\hline Education: Form IV and above (yes $=1$, no $=0$ ) & 576 & + & 0.215 & 0.41 \\
\hline Household size (number of members) & 576 & + & 4.66 & 1.64 \\
\hline Access to extension services $($ yes $=1$, no $=0$ ) & 576 & + & 0.22 & 0.411 \\
\hline Experience in farming (years) & 576 & + & 0.741 & 0.438 \\
\hline Land size (acres) & 572 & - & 1.089 & 1.050 \\
\hline Household income from horticulture (TZS) & 388 & + & $1,801,268$ & $3,292,559$ \\
\hline Management innovation $($ yes $=1$, no $=0$ ) & 576 & + & 0.314 & 0.465 \\
\hline Access to credit $($ yes $=1$, no $=0)$ & 576 & + & 0.357 & 0.479 \\
\hline $\begin{array}{l}\text { Good perception of horticulture for agribusiness } \\
\qquad(1=\text { yes, } 0=\text { poor })\end{array}$ & 576 & + & 0.747 & 0.434 \\
\hline Improved packaging $($ yes $=1$, no $=0)$ & 576 & + & 0.212 & 0.409 \\
\hline Improved storage facilities (yes $=1$, no $=0$ ) & 576 & + & 0.227 & 0.4353 \\
\hline Improved transport facility $($ yes $=1$, no $=0$ ) & 576 & + & 0.272 & 0.445 \\
\hline
\end{tabular}

$\mathrm{N}=$ Number of respondents, $\mathrm{SD}=$ Standard deviation.

\subsubsection{Shapiro-Wilk Test}

The Shapiro-Wilk test was used to test the hypothesis that the variables are normally distributed [28]. If the $p$-value is less than the chosen alpha level, the null hypothesis is rejected, implying that the tested variables are not normally distributed. If the $p$-value is greater than the chosen alpha, the null hypothesis is not rejected. In this case, the tested variables are normally distributed. The Shapiro-Wilk test (W) was based on the formula provided in Equation (5) as:

$$
\mathrm{W}=\frac{\left(\sum_{\mathrm{i}=1}^{n} \mathrm{a}_{\mathrm{i}} \mathrm{x}_{(\mathrm{i})}\right)^{2}}{\sum_{\mathrm{i}=1}^{n}\left(\mathrm{x}_{\mathrm{i}}-\overline{\mathrm{x}}\right)^{2}}
$$


where $x_{i}$ are the ordered sample value, $\bar{x}$ is a sample mean, $a_{i}$ constants are generated from the means, variances, and covariances of the order statistics of a sample of size $n$ from a normal distribution. The value of $\mathrm{W}$ lies between zero and one. Smaller values indicate the non-normal distribution of the data that leads to the rejection of normality whereas a value of one indicates normality of the data.

\subsubsection{Kruskal-Wallis H Test}

The Kruskal-Wallis H Test is a non-parametric method for testing whether samples originate from the same distribution. It was used to test the hypotheses that male and female youth experience the same crop losses in their involvement in the horticulture agribusiness. The test was used to compare two or more independent samples of equal or different sample sizes [29]. The formula for computing the Kruskal-Wallis $\mathrm{H}$ test is given in Equation (6).

$$
\mathrm{H}=\frac{12}{\mathrm{~N}(\mathrm{~N}+1)} \sum_{\mathrm{i}=1}^{\mathrm{c}} \frac{\mathrm{R}^{2}}{\mathrm{n}_{\mathrm{i}}}-3\left(\mathrm{n}_{\mathrm{i}}+1\right)
$$

where, $\mathrm{H}=$ Test- statistic for Kruskal-Wallis, $\mathrm{N}=$ Total number of observations over all samples, $R^{2}=$ Square of the sum of rank for samples $i, c=$ number of samples, $n_{i}=$ sample size of sample $i$.

The decision rule states that the rejection for the $\mathrm{H}$ test is $\mathrm{H}>\chi^{2}$ where $\chi^{2}$ is based on $(\mathrm{c}-1)$ degree of freedom $(p \leq 0.05)$.

$$
\chi^{2}=\frac{\sum\left(\mathrm{f}_{\mathrm{n}}-\mathrm{f}_{\mathrm{e}}\right)^{2}}{\mathrm{f}_{\mathrm{e}}}
$$

where $f_{n}=$ observed frequencies in each cell.

$\mathrm{f}_{\mathrm{e}}$ can be computed as:

$$
\mathrm{f}_{\mathrm{e}}=\frac{\mathrm{R} \times \mathrm{C}}{\mathrm{N}}
$$

where, $\mathrm{R}=$ Row total, $\mathrm{C}=$ Column total, and $\mathrm{N}=$ Number of cases. The decision rule used in this test is that if $\chi^{2}$ calculated is greater than $\chi^{2}$ tabulated, the null hypothesis $\left(\mathrm{H}_{0}\right)$ that male and female youth experience same crop losses in their involvement in horticulture is rejected.

The estimated $\mathrm{H}$ follows $\chi^{2}$ distribution with (c-1) degree of freedom as indicated in Equation (6).

\section{Results and Discussion}

\subsection{The Extent of Male and Female Youth Involvement in Horticulture Agribusiness}

Results show that male youth dominate in horticultural agribusiness (59.6\%) compared to female youth. This might be due to the labor-intensive nature of the sub-sector which could be very tiresome and time consuming for female youth who must integrate this activity with other labor-intensive family and domestic responsibilities. In addition, Table 2 shows that male access to credit is high $(41 \%)$ compared to female youth (36\%). Additionally, access to land and capital could be a limiting factor for female youth to be more involved in the horticulture sub-sector since most African societies do not allow women to inherit family land. Additionally, results in Figure 3 show that male youth experienced the highest crop losses of $44.5 \%$ for amaranthus (Amaranthus cruentus) and the lowest crop losses of $10 \%$ for Chinese mallow (Malva verticillata), while female youth experienced the highest crop losses of $32.1 \%$ for tomato (Solanum lycopersicum) and the lowest crop losses of $2.5 \%$ for amaranthus. The highest crop losses experienced by male youth might be attributed to their lack of experience in selling amaranthus in the open markets; instead, they sell directly at the farm gates compared to female youth who are used to sell vegetables by the roadsides. The female highest crop losses in tomato are attributed because female youth have limited access to market information compared to their male counterparts. Female youth also tend to use rudimentary packaging material like baskets commonly called "Tenga". The high crop losses in turn limited involvement of female youth in the tomato value chain. Respondents of focus group discussions explained that low access to market places in some 
villages also contributed to the increased crop losses. Most farmers sell their produces during the harvesting season, resulting in oversupply and low payments. The low economic returns in turn discourage the youth from engaging in the value chains.

Table 2. Access to credit among male and female youth.

\begin{tabular}{cccc}
\hline Gender & N & Mean & SD \\
\hline Male & 343 & 0.41 & 0.49 \\
Female & 233 & 0.36 & 0.48
\end{tabular}

$\mathrm{N}=\overline{\text { Number of respondents, } \mathrm{SD}=\text { Standard deviation }}$.

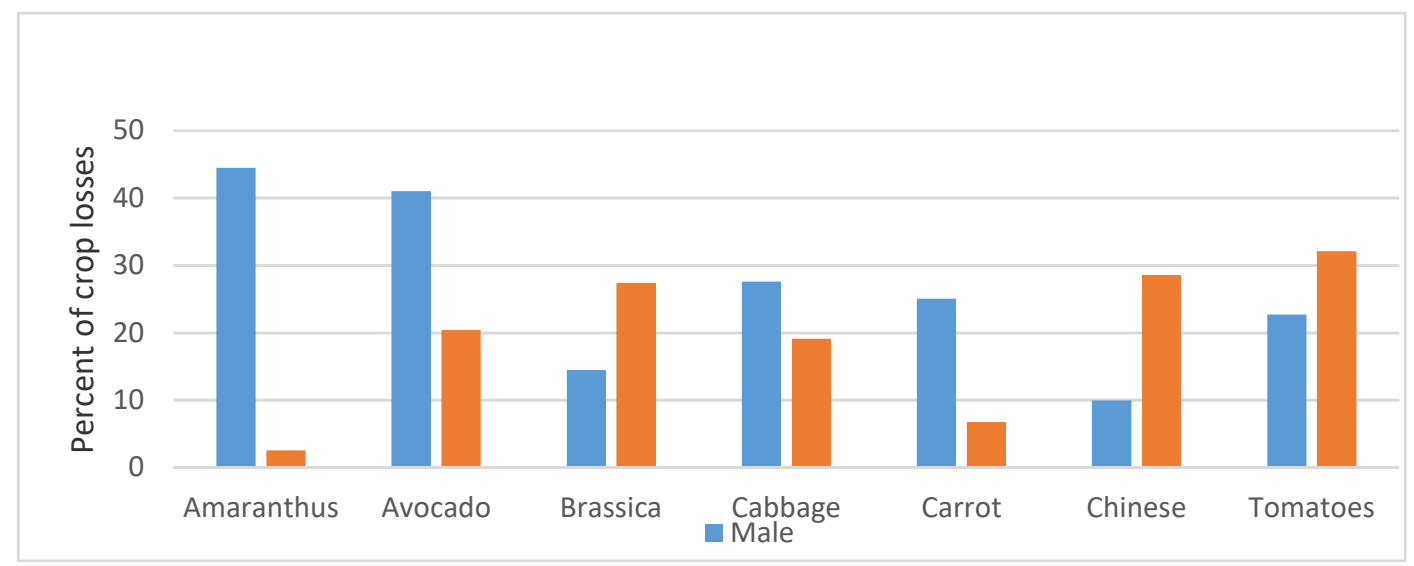

Figure 3. The extent of crop losses in horticultural crops produced by gender.

Table 1 shows the demographic and socioeconomic characteristics of the respondents $(n=576)$. The majority of the respondents had primary school education $(63.5 \%)$. This could emanate from the fact that youth who have acquired some basic education is in a good position to participate in horticulture agribusiness and to adopt PHM innovations. This result is in conjunction with earlier empirical studies by [30] who found that youth who have acquired some form of education are more likely to adopt and participate in new farming activities like horticulture activities earlier and faster than the uneducated youth. Similarly, Ref. [31] noted that educated people could have a moderate degree of awareness about agricultural activities including horticulture PHM innovations.

Results also show that most of the respondents $(74 \%)$ have experience in farming. This indicates that experience in farming is an important determinant for youth involvement in horticulture agribusiness. Youth with more experience in farming tend to adopt new ideas and innovations and participate in horticulture agribusiness compared to youth with less experience in farming. This is because youth with more experience in farming have some technical knowledge associated with the risks of PHLs and ways to reduce them compared to youth with little or no experience. This finding is similar to the study by [32] who noted that farming experience (correlates with the acquisition of improved skills in agricultural activities such as in horticultural agribusiness.

\subsubsection{Factors Influencing Youth Involvement in Horticulture Agribusiness}

Results in Table 3 are from the ordered logit model analysis used to estimate factors influencing male and female youth involvement in horticulture agribusiness in Tanzania with regards to PHM innovations. The three categories of level of involvement were specified as follows: not involved, part-time, and full-time involvement that formed the dependent variable as ordered 0,1 , and 2, respectively. Out of the 15 explanatory variables specified in the model, 8 significantly contributed to male and female youth involvement in horticulture agribusiness. The model reveals that the $\log$-likelihood ratio of 243.6 is highly significant $(p \leq 0.000)$. The explanatory power of the model is 
good and that variability of the dependent variables or the decision to be involved in horticulture agribusiness is associated with the specified independent variables.

Table 3. Ordered logit model used to estimate factors influencing male and female youth involvement in horticulture agribusiness.

\begin{tabular}{ccccc}
\hline Variable Name & Odds Ratio & Std. Error & $\mathbf{z}$ & $p>\mathbf{z}$ \\
\hline Education: Primary education & $9.712^{* * *}$ & 3.601 & 6.13 & 0.000 \\
Education: Form IV and above & $2.022^{*}$ & 0.791 & 1.8 & 0.072 \\
Marital status (married) & 0.933 & 0.274 & -0.24 & 0.814 \\
Gender female & $0.523^{* *}$ & 0.138 & -2.46 & 0.014 \\
Land size & $0.786^{*}$ & 0.099 & -1.91 & 0.057 \\
Access to extension services & 0.942 & 0.302 & -0.19 & 0.852 \\
Experience in farming & 0.997 & 0.28 & -0.01 & 0.991 \\
Household size & 1.069 & 0.083 & 0.86 & 0.392 \\
Management innovation & $8.883^{* * *}$ & 3.225 & 6.02 & 0.000 \\
Access to credit & $1.617^{*}$ & 0.449 & 1.73 & 0.083 \\
Good perception of horticulture for agribusiness & $5.289^{* * *}$ & 1.674 & 5.26 & 0.000 \\
Household income from horticulture & 1.103 & 0.111 & 0.98 & 0.33 \\
Improved packaging & $2.701^{* * *}$ & 0.985 & 2.73 & 0.006 \\
Improved storage facility & 0.877 & 0.266 & -0.43 & 0.666 \\
Improved transport & 1.514 & 0.55 & 1.14 & 0.254 \\
\hline
\end{tabular}

$\mathrm{z}$ is the ratio of the coefficient to the standard error of the respective predictor. Source; computed by authors using Stata software (StataCorp, College Station, TX, USA), data from field survey 2018. Observation $=385$, log-likelihood $=-243.6$, Pseudo $R^{2}=0.3186$, Chi-square $=227.89$. Asterisks represent statistically significant at ${ }^{* * *} 1 \%,{ }^{* *} 5$, and $* 10 \%$, respectively.

The variable "Primary education" is positive and significant at $1 \%$ influencing male and female youth involvement in horticulture agribusiness with regards to PHM innovations. This implies that youth who completed primary school education are more likely to be involved in horticulture agribusiness by about 9.7 times (odds $=9.7$ ) compared with youth who have a high level of education. The variable "Form IV and above" is also positive and significant at $10 \%$. This implies that youth who attained high-level education are more likely to involve in horticulture agribusiness in a small proportion of 2 times (odds $=2$ ) compared to primary school education. This implies that youth who completed primary school education see horticulture as a major income-generating activity in rural areas since they have limited options for jobs compared with youth who acquire higher-level education. Youth who have more education have more choices and they opt to work in non-farming activities or in urban areas and they regard horticulture as labor-intensive and a job for uneducated people. Hence very few educated youths can be found in horticulture agribusiness. Therefore, there is a need to increase awareness among youth who have a better education to remain in their respective localities and utilize the knowledge received in horticulture PHM, which in turn could reduce horticulture PHLs as well as increase productivity and income among the youth, leading to a reduction of youth unemployment. This recommendation is in conjunction with earlier empirical studies by [33] and [30] who found that youth who have acquired some form of education are more likely to adopt and participate in new farming activities like horticulture agribusiness. These similarities imply that formal education plays a significant role in the enlightenment of youth toward identifying economic opportunities like involvement in horticulture agribusiness.

The results further reveal that the variable "Gender female" is negative and significant at $5 \%$. This indicates that female youth are less likely to be involved in the horticulture sub-sector by 0.52 times (odds $=0.52$ ) compared with their male counterparts. This implies that female youth involvement in horticulture agribusiness is a challenge because females have to integrate it with their domestic responsibilities of taking care of the family, cooking, and other household chores. Similarly, horticulture activities are more labor-intensive, time-consuming, and capital-intensive and may contribute to the low participation of female youth in horticulture agribusiness. This result disagrees with that of Adejo et al. [34] in their study on the Assessment of Postharvest Management Information Needs 
of Yam Farmers in Kogi State, Nigeria. Their results found that gender has no significant effect on improved postharvest management technologies, probably because they have no access to information on those technologies. The difference between these findings denotes that gender issues vary from one society to another due to historical factors, environmental factors, and culture of a society. Taking the case of developing countries, women's insecure rights to land exclude them from participation in decision making over land and natural resource use as a result of colonial ideals. For example, men play the main role in economic development, therefore will be the beneficiaries of education, training, and technology compared to women [35]. Additionally, Ref. [36] in their study for Gender and Employment in Kenya horticulture Value Chain found that entitlements to land are not uniform among male and female due to Kinship norms that provide women with land rights through marriage and again they had no choice of what to produce. Moreover, in Tanzania men are primary decision-makers about what to plant since they are often the owner of the plots due to customary patrilineal land practices and gender norms regarding farm activities [37].

Land size is negative and significant at $10 \%$. This implies that a unit increase in land size reduces the probability of youth involvement in horticulture activities by 0.78 times (odds $=0.78$ ). This means that as land size increases, youth may reduce their involvement in horticulture agribusiness and shift to non-horticultural crops such as potatoes, maize, and beans. This is because horticultural crops are often grown in small plots because is more labor- and capital-intensive. Hence, the increase in land size may increase the costs of operation and management, which could be difficult for the youth to sustain due to financial constraints, which most youth face. Moreover, prices of horticultural produce are not stable, leading to monetary loss due to changing prices in the markets, making the cost of operations high compared to income received.

During focus group discussions, respondents reported that prices for one box of tomato ranged from TZS 15,000 to TZS 35,000 per season, while the price for one kilogram of avocado ranged from 500 to 1500 per season. They added that the price for one kilogram of leafy vegetables might fluctuate from 100 to 500 per season.

Additionally, both male and female youth in the Njombe region in November 2018 emphasized that the absence of processing plants to add value to horticultural produce to reduce PHLs could limit youth involvement in horticulture agribusiness.

Management innovation is positively and significantly associated with the dependent variable at $1 \%$. This shows that youth with management innovations are more likely to be involved in horticulture agribusiness by 8.9 times (odds $=8.9$ ) compared with youth with no management innovation. This implies that youth who have knowledge and techniques on how to reduce PHLs are more likely to be involved in the horticulture sub-sector due to the awareness and knowledge they have on how to tackle PHLs.

Access to credit has a positive significant association at $10 \%$. Youth with access to credit is more likely to be involved in horticulture agribusiness by 1.6 times (odds $=1.6$ ) compared with youth who have no access to credit. Access to credit can help youth acquire improved variety and access to PHM innovations (harvesting tools, packhouses, transport equipped with cold store facilities, use of shade, plastic crates, and processing plants) which are vital in horticulture sub-sector development.

Furthermore, a good perception of horticulture as a good business is positive and significant at $1 \%$. This implies that male and female youth who perceive horticulture as good business are more likely to be involved in horticulture agribusiness by 5.3 times (odds $=5.3$ ). This is motivated by the highest expected returns from horticulture agribusiness. This result is in line with earlier empirical results by [38] in their study found that youth have a positive perception of agriprenuership. This result shows that youth who have a positive perception of the agriculture sector is more likely to involve in horticulture agribusiness compared to youth who have a negative perception.

Improved packaging materials positively and significantly influences the dependent variable at $1 \%$. Youth with access to improved packaging material such as plastic crates are more likely to be involved in horticulture activities by 2.7 times (odds $=2.7$ ) than those with no access to improved 
packaging material. This implies that youth who use improved packaging material could incur low crop losses compared to those who use local packaging material like baskets.

\subsubsection{Results of the Shapiro-Wilk Test}

Shapiro-Wilk test (W) was used to test whether variables are normally distributed. This is because if data are not normally distributed some of the econometric assumptions are violated which may lead to wrong results. The Shapiro-Wilk (W) test indicates that all variables were approaching one (Table 4). Hence the variables followed a normal distribution.

Table 4. Shapiro-Wilk (W) test for normal data distribution.

\begin{tabular}{cccccc}
\hline Variable & $\mathbf{N}$ & $\mathbf{W}$ & $\mathbf{V}$ & $\mathbf{z}$ & Prob > z \\
\hline Household size & 576 & 0.9832 & 6.419 & 4.498 & 0.000 \\
Land size & 572 & 0.85982 & 53.24 & 9.612 & 0.000 \\
Experience in horticulture agribusiness & 576 & 0.99548 & 1.728 & 1.324 & 0.093 \\
Household income from horticulture & 388 & 0.99064 & 2.508 & 2.185 & 0.014 \\
\hline
\end{tabular}

$\mathrm{N}=$ Number of respondents; $\mathrm{W}=$ Wilk test; $\mathrm{V}=$ Variances; $\mathrm{z}=$ the ratio of the coefficient to the standard error of the respective predictor.

\subsubsection{Postharvest Losses among Male and Female Youth Involved in Horticulture Agribusiness}

Results of the Kruskal-Wallis equality-of-population-rank test show that male and female youth experience different crop losses in the horticulture agribusiness as indicated in the chi-square (8.7) and p-values $(p \leq 0.01)$ that are statistically significant (Table 5). Hence, we reject the null hypothesis that male and female youth experience the same crop losses in the horticulture agribusiness. Female youth experience lower crop losses in some crops such as amaranthus and carrot than their male counterparts. This finding is supported by the results of the descriptive analysis which shows that male youth experience higher crop losses compared with female youth (Figure 3). This finding is in agreement with [39] in their studies in Oyo State, Nigeria, who reported that there is a significant difference in losses experienced by male and female farmers in watermelon production. The similarities could emanate from the common practice of assigning females to engage in postharvest activities like sorting and grading compared with their male counterparts in rural areas of Africa.

Table 5. Kruskal-Wallis Equality-of-Populations-Rank Test.

\begin{tabular}{ccc}
\hline & Observation & Rank Sum \\
\hline Male & 207 & $41,422.5$ \\
Female & 163 & $27,212.5$ \\
Chi-squared $=8.766(1$ d.f $)$ & & \\
Probability $=0.0031^{*}$ & & \\
Chi-square with ties $=8.7$ ( 1 d. f) & & \\
Probability $=0.0031^{*}$ & \\
\hline d.f represents a degree of freedom. Asterisks represent statistically significant at $1 \%$.
\end{tabular}

\subsubsection{Proportions of Crop Losses}

Results from the survey reveal that the proportion of crop losses varied across the stages of crop management. For instance, a higher level of losses was reported at grading $(24.83 \%)$, harvesting $(23.45 \%)$, and handling $(19.31 \%)$ stages. Lower crop losses were reported from poor agronomic practices $(15.17 \%)$, transport $(8.97 \%)$, and packaging $(8.28 \%)$ as shown in Figure 4 . The losses are mainly contributed to by the perishable nature of the crop due to their high moisture content, and improper handling during harvesting, grading, transporting, and marketing. For example, the use of bamboo baskets (called locally "Tenga") to store tomato during transportation. The "rough inside of the Tenga" could crash the fruit to the bottom, hence causing the rejection. The results from this study are in line with the 
study by Zakaria et al. [15] who found that $15 \%$ of oranges were wasted during the harvesting process, $18 \%$ during the handling process, $50 \%$ during storage, and $17 \%$ during transportation. Similarly, this study agrees with Kasso and Bekele [22] who reported that severe postharvest losses and quality deterioration of horticultural crops occurred during harvesting, marketing, transportation, and storage.

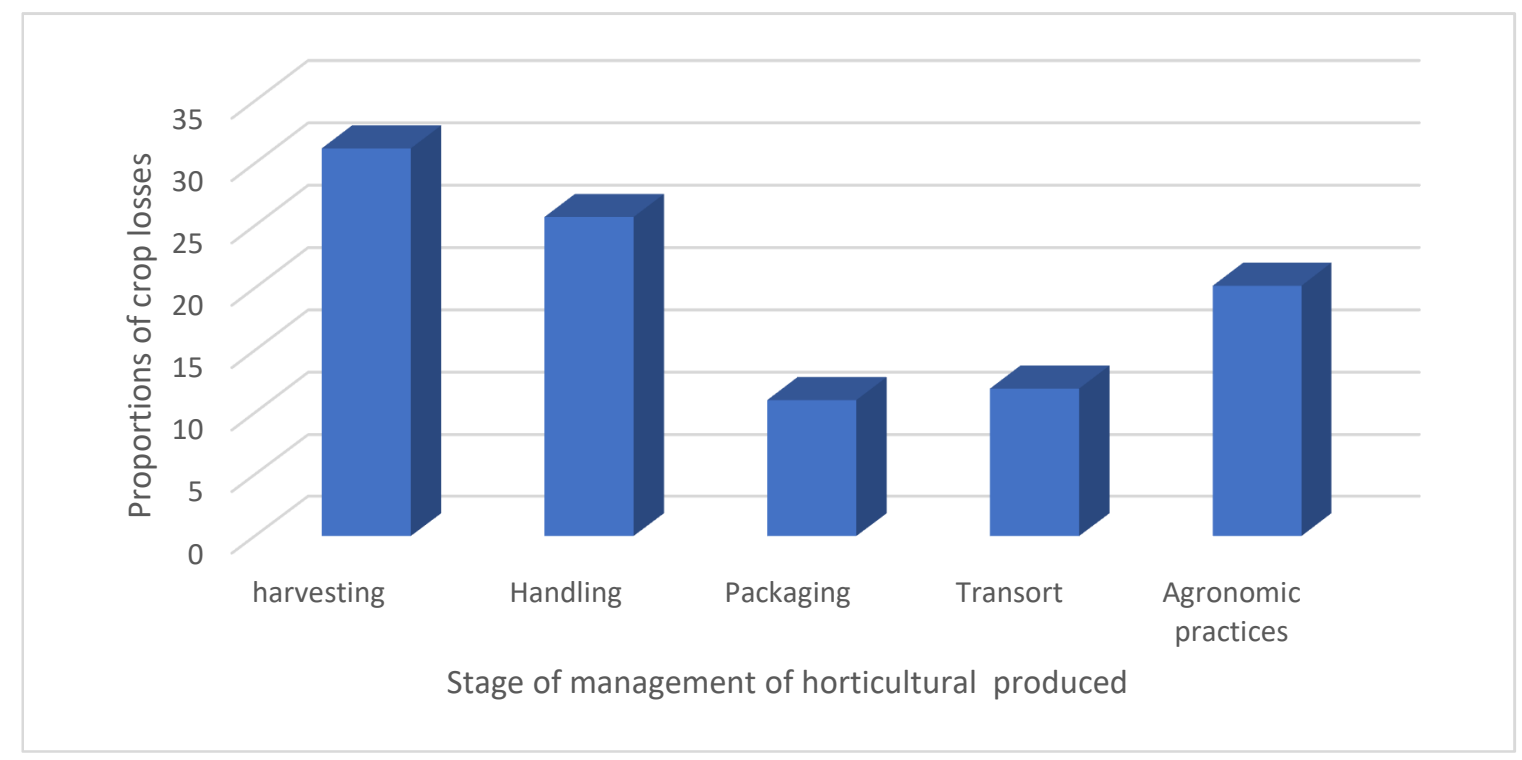

Figure 4. Proportion of crop losses at stage of management.

\subsubsection{Innovations Used to Reduce Post-Harvest Losses (PHLs) in Horticulture Agribusiness}

Results show that the majority $(68.77 \%)$ of respondents were not aware of innovations needed to reduce postharvest losses. The most common innovations used to reduce postharvest losses were grading (42.8\%) and harvesting at the coolest time of the day (35.8\%) (Figure 5). The use of improved transport facilities such as a motor van equipped with cold storage facilities (5.83\%) and the use of improved storage facilities such as pack houses is low (5.25\%). There was no mention of innovations such as cooling systems like Zero Energy Chambers, charcoal room, and harvesting tools. This implies that there is limited awareness of the innovations used to reduce PHLs among the youth.

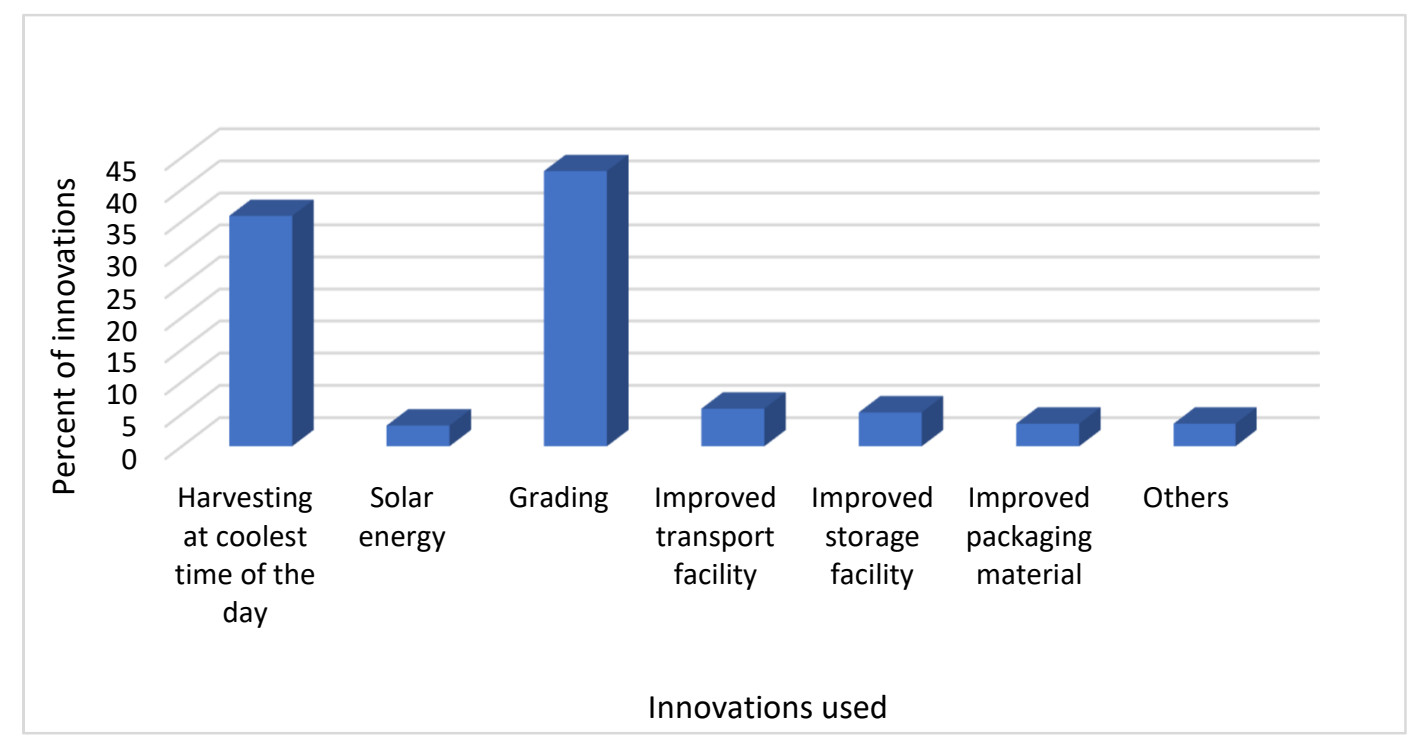

Figure 5. Postharvest Management innovation used to reduce postharvest losses. 
Generally, the framework guiding this study was useful in describing factors influencing youth involvement in horticulture agribusiness with a special focus on PHM innovation in Njombe Region as indicated above. However, the conceptual framework could be improved for further research to capture more variables like agro-processing, improved rural roads, access to ICT, marketing infrastructure, access to electricity, more investment on cold chain public logistic facilities (e.g., Cold chain warehouses at airports like Songwe International airport) and Research and Development, all important factors in reducing horticulture postharvest losses, which in turn increase the productivity of produce as well as income which could attract youth to be involved in horticulture agribusiness which in turn reduce youth unemployment problem. This should be done in partnerships between governments, youth organizations, academia, and private sectors.

\section{Conclusions and Policy Implications}

The finding reveals that male youth dominate the horticulture agribusiness. The finding points out the need to empower female youth to have full control over land use, access to credit, education, and participation in decision making from household to community level could attract them to increase participation in horticulture agribusiness. Furthermore, factors that positively and significantly influence youth involvement in horticulture agribusiness are primary school education, Form IV and above, management innovation, access to credit, good perception of horticulture for agribusiness and improved packaging materials. Factors that negatively and significantly influence youth involvement in horticulture agribusiness are gender and farm size. In reviewing the literature, from difference, similar research revealed that aspirations of youth, youths' access to resources (land, finance, information), and participation in collective action encouraged youth's participation in agribusiness. Additionally, youth involved in the horticulture agribusiness face severe PHLs. The youth use grading and harvesting at the coolest time of the day, all of which are manual activities. This implies that youth in Tanzania, particularly in the Njombe Region, have limited knowledge and information on improved horticultural PHM innovations. Knowledge of the PHM innovations would have contributed to encouraging the youth involvement in the horticulture agribusiness. The following policy actions are recommended to enhance opportunities for engagement for male and female youth in horticulture agribusiness.

First, the Public-Private Partnership (PPP) approach could be used to increase the youths' awareness and knowledge of horticulture PHM innovations through formal education and agricultural extension services. The knowledge and awareness could in turn encourage more youth to participate in the horticultural agribusiness.

Second, there is a need to promote agro-processing in the industrialization policy. The policy could emphasize on creating more markets for horticulture produce, reducing post-harvest losses, and encouraging more youth to engage in horticultural agribusiness.

Third, the government should create a conducive environment (such as improved rural roads, power supply, and lowering tax in improved horticultural PHM innovations).

Fourth, infrastructure development: Youth would benefit from investments made in the construction of packhouses. Currently, there is one packhouse in Njombe Region centered in Njombe Town Council which was built through a public-private partnership between the Government and the Tanzania Horticultural Association (TAHA). This can be worked out through linking youth with organizations or companies that purchase horticultural products by small-scale farmers including youth. Additionally, the formation of youth Agricultural Marketing Cooperative Societies (AMCOS) could help the youth to pay rent for the packhouse that is expensive for an individual youth to afford since the cost per season is high, about TZS 1million (USD 435) for a storage capacity ranging from $20 \mathrm{t}$ to $80 \mathrm{t}$.

Fifth, alleviating financial constraints: Youth lack the financial resources to start and develop horticultural businesses. There is a need to create incentives for the small and medium financial institutions or microcredit financial institutions to open sub-offices in Njombe to provide credit with 
an interest rate that is affordable by youth. Such a youth-friendly credit scheme will help them to access PHM innovations.

However, this study has some limitations, these include the impact of horticulture PHLs on the welfare of rural youth, the profitability of PHM innovations, and the extend of youth's application of PHM innovations. This study provides bases for future research.

More research is needed to know to what extent youths applying the PHM innovations to reduce postharvest losses would impact on food and nutrition security, increased employment opportunities and income, as well as poverty reduction among the youths.

Author Contributions: Conceptualization, A.A.N., A.H., M.Y. and V.M.; Data curation, A.A.N.; Formal analysis, A.A.N. and A.H.; Funding acquisition, V.M.; Methodology, A.A.N., and A.H.; Software, V.M.; Supervision, A.H., M.Y. and V.M.; Validation, M.Y. and V.M.; Writing—original draft, A.A.N.; Writing—review \& editing, A.A.N., A.H., M.Y. and V.M. All authors have read and agreed to the published version of the manuscript.

Funding: This study was funded by International Fund for Agricultural Development (IFAD) under the research grant number 2000001374, 2018; "Enhancing capacity to apply research evidence in policy for youth engagement in agribusiness and rural economic activities in Africa" Project is under the International Institute of Tropical Agriculture (IITA).

Acknowledgments: Our appreciation goes to Njombe Region, districts, and village executive officers where the research took place, male and female youth for their passion throughout the interview process, enumerators who assisted with data collection and the two anonymous reviewers for their useful comments. We are indebted to Mr. Filbert Y. Kavia for providing logistical support during fieldwork. Moreover, the authors are indebted to Ms. Olatunbosun Yvonne for language editing.

Conflicts of Interest: The authors declare to have no conflict of interest.

\section{References}

1. International Labour Organization Statistics (ILOSTAT). Tanzania's Youth NEET Rate not in Employment or Training. Available online: https://ilostat.ilo.org/topics/employment/ (accessed on 27 April 2020).

2. Tanzania National Bureau of Statistics. 2012 Population and Housing Census. Population Distribution by Administrative Areas; National Bureau of Statistics, Ministry of Finance: Dar es Salaam, Tanzania, 2013. Available online: https://www.nbs.go.tz/index.php/en/census-surveys/population-and-housing-census/1622012-phc-population-distribution-by-administrative-areas (accessed on 28 April 2020).

3. Ministry of Agriculture Livestock and Fisheries. National Strategy for Youth Involvement in Agriculture (NSYIA) 2016-2021; Ministry of Agriculture Livestock and Fisheries: Dar es Salaam, Tanzania, 2016.

4. The United Republic of Tanzania, Ministry of Agriculture. Budget Speech, Ministry of Agriculture. 2019. Available online: https://www.kilimo.go.tz/index.php/en/resources/view/hotuba-ya-waziri-wa-kilimomheshimiwa-japhet-ngailonga-hasunga-mb-kuhusu-ma (accessed on 27 April 2020).

5. Akpan, S.B.; Patrick, I.V.; James, S.U.; Agom, D.I. Determinants of Decision and Participation of Rural Youth In Agricultural Production: A case Study of Youth in Southern Region of Nigeria. Russ. J. Agric. Socio-Economic Sci. 2015, 7, 35-48. [CrossRef]

6. Yami, M.; Feleke, S.; Abdoulaye, T.; Alene, A.D.; Bamba, Z.; Manyong, V. African rural youth engagement in agribusiness: Achievements, limitations, and lessons. Sustainability 2019, 11, 185. [CrossRef]

7. United Republic of Tanzania (URT). Agricultural Sector Development Programme Phase II (ASDP II); Government Printer: Dar es Salaam, Tanzania, 2017.

8. United Republic of Tanzania (URT). Tanzania Agriculture and Food Security Investment Plan(TAFSIP); Government Printer: Dar es Salaam, Tanzania, 2011.

9. United Republic of Tanzania (URT) National Agricultural Policy; Government Printer: Dar es Salaam, Tanzania, 2013.

10. Tanzania Horticulture Association (TAHA). Scoping Project: Tanzania's Horticulture Industry Business Opportunities; Netherlands Enterprise Agency: Utrecht, The Netherlands, 2018.

11. The United Republic of Tanzania (URT), Ministry of Agriculture. Budget Speech, Ministry of Agriculture. 2018. Available online: https:/www.kilimo.go.tz/index.php/en/resources/view/hotuba-ya-mheshimiwawaziri-wa-kilimo-mhe.-eng.-dkt.-charles-j.-tizeba-mb-k (accessed on 27 April 2020). 
12. Horticultural Deveopment Council of Tanzania (HODECT) Tanzania Horticultural Development Strategy 2012-2021; Government Printer: Dar es Salaam, Tanzania, 2010.

13. Kitinoja, L.; Saran, S.; Roy, S.K.; Kader, A.A. Postharvest technology for developing countries: Challenges and opportunities in research, outreach and advocacy. J. Sci. Food Agric. 2011, 91, 597-603. [CrossRef]

14. FAO. Global Food Losses and Food Waste_Extent, Causes and Prevention; Food and Agriculture Organization of the United Nations: Rome, Italy, 2011.

15. Zakaria, M.; Rehema, E.; Mariam, M.; Mtunguja, K. Assessment of Orange Losses and Existence of Post-Harvest Methods (PHM) Along the Coast Belt of Tanzania. J. Biol. Agric. Healthc. 2014, 4, 14-21.

16. AGRA. Africa Agriculture Status Report: Climate Change and Smallholder Agriculture in Sub-Saharan Africa; Alliance for Green Revolution Africa (AGRA): Nairobi, Kenya, 2014; ISBN 978-92-990054-4-6.

17. Hodges, R.J.; Buzby, J.C.; Bennett, B. Postharvest losses and waste in developed and less developed countries: Opportunities to improve resource use. J. Agric. Sci. 2011, 149, 37-45. [CrossRef]

18. Kimaro, P.J. Determinants of Rural Youth ' S Participation In Agricultural Activities: The Case of Kahe East Ward in Moshi Rural District, Tanzania. Int. J. Econ. Commer. Manag. 2015, III, 1-47.

19. Nnadi, F.N.; Akwiwu, C.D. Determinants of Youths' Participation in Rural Agriculture in Imo State, Nigeria. J. Appl. Sci. 2008, 8, 328-333. [CrossRef]

20. Adekunle, O.; Adefalu, L.; Oladipo, F.; Adisa, R.; Fatoye, A. Constraints to Youths' involvement in Agricultural Production in Kwara State, Nigeria. J. Agric. Ext. 2010, 13, 102-108. [CrossRef]

21. Addo, J.K.; Osei, M.K.; Mochiah, M.B.; Bonsu, K.O.; Choi, H.S.; Kim, J.G. Assessment of Farmer Level Postharvest Losses along the Tomato Value Chain in Three Agro-Ecological Zones of Ghana. Int. J. Res. Agric. Food Sci. 2015, 2, 15-23.

22. Kasso, M.; Bekele, A. Post-harvest loss and quality deterioration of horticultural crops in Dire Dawa Region, Ethiopia. J. Saudi Soc. Agric. Sci. 2018, 17, 88-96. [CrossRef]

23. Naing, L.; Winn, T.; Rusli, B.N. Practical Issues in Calculating the Sample Size for Prevalence Studies. Arch. Orofac. Sci. 2006, 1, 9-14.

24. Agresti, A. Analysis of Ordinal Categorical Data; Wiley Series in Probability and Statistics; John Wiley and Sons Inc.: Hoboken, NJ, USA, 2012; ISBN 9780470594001.

25. Chang, L.Y.; Wang, H.W. Analysis of traffic injury severity: An application of non-parametric classification tree techniques. Accid. Anal. Prev. 2006, 38, 1019-1027. [CrossRef] [PubMed]

26. Greene, W.H. Econometric Analysis, 5th ed.; Pearson Education, Inc.: Upper Saddle River, NJ, USA, 2003; ISBN 0130661899.

27. Kaplan, S.; Prato, C.G. Risk factors associated with bus accident severity in the United States: A generalized ordered logit model. J. Safety Res. 2012, 43, 171-180. [CrossRef] [PubMed]

28. Shapiro, S.S.; Wilk, M.B. An Analysis of Variance Test for Normality (Complete Samples). Biometrika 1965, 52, 591. [CrossRef]

29. Kruskal, W.H.; Wallis, W.A. Use of Ranks in One-Criterion Variance Analysis. J. Am. Stat. Assoc. 1952, 47, 583-621. [CrossRef]

30. Etim, N.A.; Udoh, E.J. Willingness of Youths to Participate in Agricultural Activities: Implication for Poverty Reduction. Am. J. Soc. Sci. 2018, 6, 1-5.

31. Cheteni, P. Youth Participation in Agriculture in the Nkonkobe District Municipality, South Africa. J. Hum. Ecol. 2016, 55, 207-213. [CrossRef]

32. Lawal, A.M.; Omotesho, O.A.; Falola, A. Technical efficiency of youth participation in agriculture: A case study of the youth in agriculture programme in Ondo state, South Western Nigeria. Niger. J. Agric. Food Environ. 2009, 5, 20-26.

33. Diao, X.; Magalhaes, E.; Mcmillan, M. Understanding the Role of Rural Non-Farm Enterprises in Africa's Economic Transformation: Evidence from Tanzania. J. Dev. Stud. 2018, 54, 833-855. [CrossRef]

34. Adejo, P.; Okwu, J.; Okwoche, V. Assessment of Post-harvest Management Information Needs of Yam Farmers in Kogi State, Nigeria. Int. J. Agric. Sci. Res. Technol. Ext. Educ. Syst. 2015, 5, 35-43.

35. Boserup, E.; Tan, S.F.; Toulmin, C.; Kanji, N. Woman's Role in Economic Development; Routledge: Abingdon, UK, 2013; ISBN 9781315065892.

36. Dolan, C.S.; Sutherland, K. Gender and Employment in the Kenya Horticulture Value Chain (Globalisation and Poverty Discussion Paper 8); Institute of Development Studies, Sussex University: Brighton, UK, 2002. 
37. Bullock, R.; Gyau, A.; Mithoefer, D.; Swisher, M. Contracting and gender equity in Tanzania: Using a value chain approach to understand the role of gender in organic spice certification. Renew. Agric. Food Syst. 2018, 33, 60-72. [CrossRef]

38. Magagula, B.; Tsvakirai, C.Z. Youth perceptions of agriculture: Influence of cognitive processes on participation in agripreneurship. Dev. Pract. 2020, 30, 234-243. [CrossRef]

39. Odebode, S.O.; Aboderin, O.S.; Aboderin, O.O. Gender Assessment of Watermelon Production among Farmers in Ibarapa Area of Oyo State. Int. J. Gend. Women's Stud. 2018, 6, 100-110. [CrossRef]

(C) 2020 by the authors. Licensee MDPI, Basel, Switzerland. This article is an open access article distributed under the terms and conditions of the Creative Commons Attribution (CC BY) license (http://creativecommons.org/licenses/by/4.0/). 